\title{
Adaptive Response of the Heart and Peripheral Vasculature on Single Physical Exereises in Experiment
}

DOI: 10.17691/stm2015.7.2.07

Received November 19, 2014

O.V. Biryukova, DSc, Professor, Department of Normal Anatomy;

N.A. Baranov, PhD, Senior Researcher, Problem Scientific Group of Adaptation Morphology;

T.I. Vasyagina, PhD, Senior Researcher, Electron Microscopy Unit, Central Scientific Research Laboratory

Nizhny Novgorod State Medical Academy, 10/1 Minin and Pozharsky Square, Nizhny Novgorod,

603005, Russian Federation

The aim of the investigation was to assess the parameters of urgent adaptation of the heart and peripheral vasculature to single physical exercises to determine an individually safe value of motor activity.

Materials and Methods. The experiments were carried out on 84 mongrel male dogs. Physical exercises were modeled in laboratory environment by treadmill run. Three types of exercises were used in the experiment: mild, optimal and excessive. Exercise duration was controlled individually, for each animal considering cardio-respiratory system state by heart rate. Cardiac work was assessed by echocardiography and electrocardiography, peripheral circulation — by hindleg rheovasogram.

Results. Experimental findings indicate significant alterations in cardiac conducting system under single physical exercises. A single mild exercise causes the increase of minute blood output due to heart rate increase. Hind leg muscular blood filling decreases. An optimal exercise results in minute blood output increase due to stroke blood volume growth. Myocardial contractility increases. Muscular blood filling rises. In excessive load increased stroke output is accompanied by left ventricular cavity dilatation. Pulse volume decreases, peripheral vasculature elasticity reduces, and hind leg muscular venous outflow gets worse.

Conclusion. Urgent adaptation of the heart and peripheral vasculature in single physical exercises shows as a marked response to a simulated factor. The technique to assess the body adaptation considering cardiovascular system condition enables to calculate individual volume of physical activity and develop recommendations for it to be used efficiently in medicine.

Key words: cardiac adaptive responses; physical exercises; treadmill test.

Currently, there has been gathered a great deal of evidence of positive and negative changes in the body resulted from physical exercises [1-5, et al.]. Most researches deal with the study of systematic exercises, long-term training programs. However, intensive physical activity has a positive effect only if used efficiently. Among the causes limiting the adaptation process to hyperkinesia the main one is the discrepancy between morphofunctional characteristics of the heart and vessels and physical exercise intensity, and accordingly disturbed formation rate of specific alterations [6]. Oxygen from the environment is transported to the working muscles by a complex of systems and organs presenting a certain conditional cardio-respiratory system, or oxygen transport system. Each component of the system can determine the oxygen transport sufficiency on exertion, however, in actual practice the main limiting component in oxygen transport system in intensive muscular activity is circulation [7].

Single exercise tests, or stress tests, are widely used to diagnose cardio-respiratory system condition in occupational selection of those who are to work under extreme conditions [8], in different sports [9-12], to determine functional reserve of organs and systems [13, 14], as well as in rehabilitation medicine and cardiology $[15,16]$. However, there are still unsettled problems related to the determination of individually safe load of physical activity and early diagnostics of over-stress events and overexertion.

The aim of the investigation was to assess the parameters of urgent adaptation of the heart and peripheral vasculature to single physical exercises to determine an individually safe value of motor activity.

Materials and Methods. The experiments were carried out on 84 mongrel male dogs aged from 1.5 to 3 years weighing $10-15 \mathrm{~kg}$. The experiments were performed in accordance with the European Convention for Protection of Vertebrate Animals Used with Experimental and Other Scientific Purposes (the Convention took place in Strasbourg on March, 18, 1986 and was confirmed in Strasbourg on June, 15, 2006).

The following single exercises were used: mild (light) -23 animals, optimal (moderate) -37 animals, and excessive (severe) -24 animals. Mild exercises

For contacts: Vasyagina Tatiyana Ivanovna, e-mail: tvasyagina@yandex.ru 


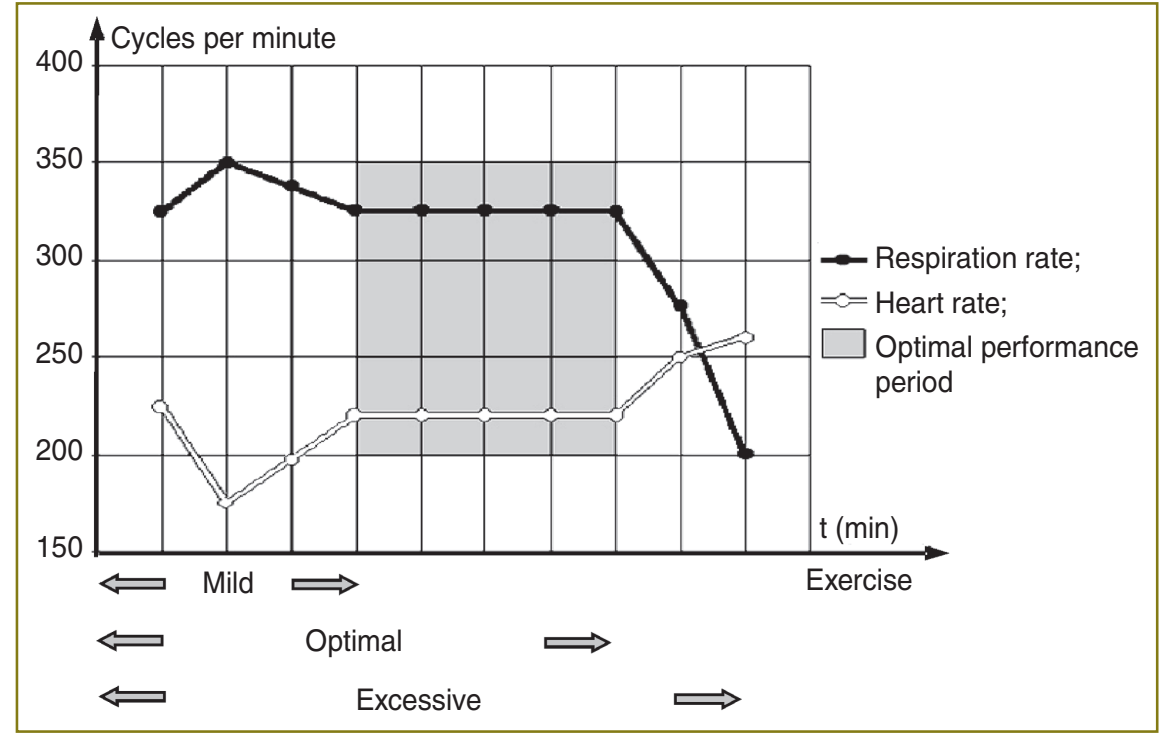

Diagram of adaptive reaction of cardio-respiratory system in single dosed physical exercises

are the most common ones in everyday life, though their effect on the body is understudied. Optimal exercises are used as endurance training, and excessive exercises are frequently used in Olympic and professional sports to determine functional capabilities of the body.

Physical activity was modeled in laboratory environment by treadmill run. Body state under physical exercise is easy to diagnose by the dynamics of heat rate $(\mathrm{HR})$ and respiration rate [17], therefore, the running time was dosed for each animal individually considering its functional state of cardio-respiratory system (See Figure). Exercise HR and respiration rate were recorded per a minute on a 4-channel electroencephalograph EEG-1 (Russia).

Echocardiograms (echoCG) were recorded on echocardiograph EKS-M-02 (Russia). Using M-mode echocardiography we studied the following parameters of the left ventricle (LV): systolic and diastolic posterior wall thickness, increment percentage of systolic thickness of the left ventricular wall, systolic and diastolic volume, stroke and minute output, ejection fraction, LV mass, velocity of myocardial contractility.

Peripheral circulation in dogs was assessed by hindleg rheovasogram, the latter being recorded on rheograph RG4-01 (Ukraine). We measured the following parameters: amplitude of systolic and diastolic waves; maximum, rapid and reduced filling time; cycle time. Relying on these parameters we calculated the following indices:

1. Rheographic index $(R I)$ is the ratio of systolic wave amplitude $(A)$ to the value of the calibration signal $(n)$. It characterizes pulse volume of the organ: $R I=A / n$.

2. Amplitude-frequency index $(A F I)$ is the ratio of $R I$ to the distance between $R$ waves in an electrocardiogram. It characterizes blood flow value in the area of interest during a period of time: $A F I=R I / R R$.

3. Diastolic index $(D I)$ is the ratio of diastolic wave amplitude value $(B)$ to systolic wave amplitude value $(A)$. It characterizes arterial and venous blood flow ratio: $D I=B / A$.

4. Maximum filling index (Imax.f) is the ratio of maximum filling time $(E)$ to cycle time $(T)$. It characterizes inflow vessel tone: Imax. $f=E / T$.

5. Rapid filling index $(R F I)$ is the ratio of rapid filling time $(C)$ to the cycle time $(T)$. It characterizes the tone of great inflow vessels. Time $C$ is calculated using differential rheogram according to the projection of its apex to rheovasogram: $R F I=C / T$.

6. Reduced filling index (RedFI) is the ratio of reduced filling time $(D)$ to the cycle time. It shows the tone of minor inflow vessels: $R e d F I=D / T$.

Echocardiogram and rheovasogram were taken immediately prior to and immediately after the running.

The findings were statistically processed using Statistica 10.0. We used Student t-test to compare two groups from normal distribution populations. If $p<0.05$ the differences were considered to be significant.

Results. The experiments showed the values of mild exercises to range within $8.1 \pm 0.6 \mathrm{~min}$. Mean respiration rate was $280.30 \pm 12.18$ cycle per minute. Mean HR under exercise was $207.6 \pm 9.6$ per minute. After the exercise it exceeded the initial value by $26.0 \%$, and mean LV minute output increased by $47.2 \%$, while mean velocity of systolic myocardial thickness decreased by $17.5 \%$ (Table 1). According to rheovasogram findings (Table 2) rheographic index and amplitude-frequency index changed after a mild single exercise: they reduced by 31.9 and $28.1 \%$ respectively. Cycle time decreased by $6.7 \%$, and diastolic index - by $10.3 \%$.

Optimal exercise duration was $20.0 \pm 1.9$ min. Mean HR during the exercise was $202.8 \pm 5.1$ per minute, and after an optimal exercise it exceeded its initial value by $24.0 \%$. Mean respiration rate was $296.8 \pm 7.4$ cycle per minute. Systolic myocardial thickness increased by $20.5 \%$, minute output - by $52.8 \%$, ejection fraction by $21.9 \%$ (See Table 1). Increment percent and mean velocity of LV posterior wall systolic thickness increased by 63.0 and $41.7 \%$ respectively. The velocity of circular myocardial contraction grew by $44.7 \%$; furthermore, systolic volume decreased by $52.8 \%$ and size of LV cavity during systole - by $25.3 \%$ compared to the initial values. Total vascular elasticity remained the same as that under a mild exercise. Amplitude-frequency index increased by $38.0 \%$ compared to the initial value (See Table 2 ). 
Table 1

Echocardiogram indices in single physical exercises $(x \pm S x)$

\begin{tabular}{|c|c|c|c|c|c|}
\hline & & & & ercise intens & \\
\hline 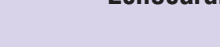 & 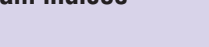 & & Mild & Optimal & Excessive \\
\hline LV posterior wall & Systolic & $1.12 \pm 0.03$ & $1.15 \pm 0.03$ & $1.35 \pm 0.04^{*}$ & $1.24 \pm 0.04$ \\
\hline thickness (cm) & Diastolic & $0.78 \pm 0.02$ & $0.80 \pm 0.03$ & $0.82 \pm 0.03$ & $0.75 \pm 0.02$ \\
\hline $\begin{array}{l}\text { Increment percen } \\
\text { systolic thickness }\end{array}$ & $\begin{array}{l}\text { LV posterior wall } \\
\text { ) }\end{array}$ & $40.8 \pm 2.2$ & $44.5 \pm 2.4$ & $66.5 \pm 5.2^{*}$ & $65.0 \pm 4.1^{*}$ \\
\hline LV volume (ml) & Systolic & $10.6 \pm 0.8$ & $9.3 \pm 1.5$ & $5.0 \pm 1.1^{*}$ & $11.6 \pm 1.5$ \\
\hline & Diastolic & $31.9 \pm 2.1$ & $33.7 \pm 3.3$ & $30.8 \pm 4.1$ & $41.8 \pm 3.4^{\star}$ \\
\hline LV output (ml) & Stroke & $21.3 \pm 1.5$ & $24.4 \pm 2.2$ & $25.8 \pm 3.6$ & $30.2 \pm 2.2^{*}$ \\
\hline & Minute & $2042 \pm 180$ & $3005 \pm 372^{*}$ & $3121 \pm 522^{*}$ & $4653 \pm 469$ * \\
\hline $\begin{array}{l}\text { Myocardial circul } \\
\text { velocity }(\mathrm{cm} / \mathrm{s})\end{array}$ & y contraction & $1.14 \pm 0.04$ & $1.21 \pm 0.07$ & $1.65 \pm 0.10^{*}$ & $1.48 \pm 0.08$ * \\
\hline $\begin{array}{l}\text { Mean velocity of } \\
\text { thickness }(\mathrm{cm} / \mathrm{s})\end{array}$ & olic myocardial & $1.20 \pm 0.06$ & $0.99 \pm 0.04$ * & $1.70 \pm 0.11$ & $1.73 \pm 0.12$ \\
\hline Ejection fraction & & $69.0 \pm 1.6$ & $74.4 \pm 2.7$ & $84.1 \pm 2.5^{\star}$ & $73.6 \pm 1.9$ \\
\hline
\end{tabular}

$\mathrm{N}$ o t e: * statistically significant difference of values with initial data; $p<0.05$.

Table 2

Rheovasogram indices in single physical exercises $(x \pm S x)$

\begin{tabular}{lcccc}
\hline \multicolumn{1}{c}{ Rheovasogram indices } & Initial level & \multicolumn{3}{c}{ Exercise intensity } \\
\hline Rheographic index (\%) & $2.54 \pm 0.20$ & $1.73 \pm 0.25^{*}$ & $3.32 \pm 0.41$ & $1.46 \pm 0.27^{*}$ \\
\hline Amplitude-frequency index (\%) & $4.06 \pm 0.33$ & $2.92 \pm 0.40^{*}$ & $5.63 \pm 0.67^{\star}$ & $3.78 \pm 0.83$ \\
\hline Diastolic index (\%) & $49.70 \pm 1.27$ & $54.80 \pm 1.93^{\star}$ & $52.80 \pm 1.74$ & $57.30 \pm 2.90^{*}$ \\
\hline Cycle time (s) & $0.59 \pm 0.01$ & $0.55 \pm 0.02^{*}$ & $0.55 \pm 0.02$ & $0.41 \pm 0.02^{*}$ \\
\hline Maximum filling index (\%) & $15.60 \pm 0.49$ & $15.60 \pm 0.82$ & $15.10 \pm 0.64$ & $19.40 \pm 1.05^{*}$ \\
\hline Rapid filling index (\%) & $10.60 \pm 0.33$ & $10.20 \pm 0.57$ & $9.80 \pm 0.52$ & $12.30 \pm 0.76$ \\
\hline Reduced filling index (\%) & $5.00 \pm 0.26$ & $5.40 \pm 0.35$ & $5.30 \pm 0.35$ & $7.20 \pm 0.67^{*}$ \\
\hline
\end{tabular}

N o t e : * statistically significant difference of values with initial data; $p<0.05$.

Excessive exercise value (before running refusal) in the animals varied greatly both in running duration from 10 to $358 \mathrm{~min}$, and in the intensity response of cardiovascular and respiratory systems. Mean HR value when running was $207.7 \pm 6.3$ per minute, the spread in values being from 158 to 261 per minute. Mean respiration rate was $298.4 \pm 7.0$ per minute, in some cases - from 190 to 350 per minute. By the moment the animals refused running HR rose sharply: by $58.7 \%$ compared the initial level, and by $35.3 \%$ compared to the optimal load level. It was not until this experiment that revealed the increase of LV cavity size by $9.3 \%$ compared to the initial one, during the previous exercise stages there was a reverse reaction. LV diastolic volume exceeded its initial level by $31.0 \%$. Stroke output increased by $41.8 \%$. Minute output rose sharply (the excess of the initial level was $127.9 \%$, the optimal exercise level - by $75.1 \%$ ). Systolic thickness of the posterior wall reduced significantly compared to the same parameter under an optimal exercise, which exceeded the resting level by $10.7 \%$ only. LV posterior wall contraction time decreased by $17.1 \%$ compared to the initial level, circulatory myocardial contraction velocity compared to an optimal load - by $14.9 \%$ but at the same time it exceeded the initial level by $29.8 \%$. Increment percent and mean velocity of the posterior wall systolic thickness, as well as LV mass remained at an optimal exercise level.

Excessive physical exercise resulted in significant decrease of rheographic index - by $42.3 \%$ compared to the initial level, while at an optimal level this parameter was recorded to grow (See Table 2). Vascular bed elasticity of hindleg muscles decreased sharply, and cycle time of rheographic wave reduced by $30.5 \%$. 
Diastolic index grew by $15.3 \%$. It is notable that only under excessive exercise there was the maximum filling increase: by $24.4 \%$ compared to the initial value. Rapid and reduced filling indices grew by 16.0 and $44.0 \%$ respectively.

Discussion. The findings analysis prompts suggestions that in mild physical activity there is urgent response of cardiovascular system: the body need for increased blood supply is responded by minute output growth, however, the increase, to a great extent, is achieved due to HR growth. Thus, central circuit of cardiac activity control is of great importance in increased blood output of the heart at this stage. Intracardiac mechanisms are not yet mobilized or at activation stage. However, mechanoelectrical feedback in the heart cannot be underestimated [18]. Reduced blood filling of hindleg muscles are likely to be related to the response lag of local control to an exercise. There is hypertension of minor inflow vessels, blood filling decrease that can be explained by the effect of sympathetic circuit control.

Under optimal load intracardiac mechanisms of cardiac activity identification switch: there is more complete LV emptying, minute output grows due to stroke output increase, myocardial contractility increases significantly. Vasculature has the signs of circulation optimization: there is the increase of blood supply of hindleg muscles, blood evacuation from the venous bed improves. According to the authors [19-21], muscular vessels dilate sequentially: at first - minor, then - the great ones. In this regard, it can be assumed that under optimal load there is the dilatation of capillaries, arteriolar capillaries and partially - arterioles.

After an excessive exercise there is the increase of stroke output (twofold compared to that under an optimal exercise) related to marked LV dilatation developed by that time. In decreased myocardial contractility, dilatation is a compensatory reaction aimed at maintaining stroke output. The mechanism of the phenomenon is shown in detail in the work [22]. The effect is reached by the decrease of myocardial tone in diastole. It enables LV walls to dilate more and contain more blood for the following output in the circulatory bed [23].

Frank-Starling mechanism does not work under excessive exercise, i.e. there is no response of contraction increase to increased myocardial dilatation, as evidenced by low increment percent of LV posterior wall systolic thickness compared to an optimal exercise. Thus, in overextension there is contraction weakening. Like under mild exercise, extracardial control of heart activity increases.

According to Korobeynikov and Priymakov [24], at the stage of submaximal exercises, the sympathetic nervous system effect on sinoatrial node prevails, while the effect of parasympathetic nervous system decreases. The increase of central control can also serve as a sign of incoordination of intracardiac control mechanisms and the body attempt to compensate these disturbances $[25,26]$.
Thus, the study of urgent adaptation of the heart and peripheral vasculature to single physical exercises showed their clear reaction on a simulated factor. Experimental findings indicate significant alterations in cardiac conducting system under single physical exercises requiring further complex morphofunctional studies.

Conclusion. The technique to assess the body adaptation considering cardiovascular system condition enables to calculate individual volume of physical activity and develop recommendations for it to be used efficiently in sports, flight and rehabilitation medicine.

Study Funding. The study was carried out under the research plan of Nizhny Novgorod State Medical Academy.

Conflicts of Interest. The authors have no conflicts of interest related to the present study.

\section{References}

1. Belotserkovskiy Z.B., Lyubina B.G., Koydinova G.A. Cardiac activity characteristics and physical performance in athletes with modified cardiac ventricular repolarization. Fiziologiya cheloveka 2009; 35(1): 90-100.

2. Laughlin M.H., Bowles D.K., Duncker D.J. The coronary circulation in exercise training. Am J Physiol Heart Circ Physiol 2012; 302(1): H10-H23, http://dx.doi.org/10.1152/ ajpheart.00574.2011.

3. Dzhelebov P.V., Gundasheva D.I., Andonova M.J., Mihaylov R.M., Slavov E.P. Effects of experimental prolonged strenuous exercise on haematological parameters in dogs. Bulg J Vet Med 2009; 12(2): 112-118.

4. Corrado D., Basso C., Thiene G. Pros and cons of screening for sudden cardiac death in sports. Heart 2013; 99(18): 1365-1373, http://dx.doi.org/10.1136/heartjnl-2012302160.

5. Rovira S., Munoz A., Benito M. Effect of exercise on physiological, blood and endocrine parameters in search and rescue-trained dogs. Veterinarni Medicina 2008; 53(6): 333-346.

6. Agadzhanyan M.G. Electrocardiographic manifestations of athletic overexertion in athletes. Fiziologiya cheloveka 2005; 31(6): 60-64.

7. Karpman V.L. Serdechno-sosudistaya sistema i transport kisloroda pri myshechnoy rabote: aktovaya rech'. V kn.: Kliniko-fiziologicheskie kharakteristiki serdechnososudistoy sistemy u sportsmenov [Cardiovascular system and oxygen transport in muscular activity: commencement address. In: Clinical medical characteristics of cardiovascular system in athletes]. Moscow; 1994; p. 12-39.

8. Panchenko L.F., Bochenkov A.A., Chermyanin S.V., Suin P.A., Fesyun A.D. Nervous and emotional tension of the flight personnel of the internal army aviation airplanes of Russian Ministry of Internal Affairs during night flights in difficult weather conditions. Vestnik OGU 2013; 155(6): 6-9.

9. Gaydash I.S., Kapustina E.V. The effect of single physical exercises on phagocytic rate of neutrophils and monocytes in blood of athletes. Zagal'na patologija ta patologichna fiziologija 2013; 8(1): 192-197.

10. Venckunas T., Lionikas A., Marcinkeviciene J.E., Raugaliene R., Alekrinskis A., Stasiulis A. Echocardiographic 
parameters in athletes of different sports. J Sports Sci Med 2008; 7(1): 151-156.

11. Neilan T.G., Ton-Nu T.T., Jassal D.S., Popovic Z.B., Douglas P.S., Halpern E.F., Marshall J.E., Thomas J.D., Picard M.H., Yoerger D.M., Wood M.J. Myocardial adaptation to short-term high-intensity exercise in highly trained athletes. J Am Soc Echocardiogr 2006; 19(10): 1280-1285, http://dx.doi. org/10.1016/j.echo.2006.05.001.

12. Kudrya O.N., Kiriyanova M.A., Kapilevich L.V. Characteristics of peripheral hemodynamics athletes with loads of adaptation to a different direction. Byulleten' sibirskoy meditsiny 2012; 3: 48-53.

13. lordanskaya F.A. Correlation analysis of adaptive parameters with possible risk factors of cardiovascular system in performance assurance in athletes. Vestnik sportivnoy nauki 2010; 5: 25-30.

14. Antelmi I., Chuang E.Y., Grupi C.J., Latorre M. do R.D. de O., Mansur A.J. Heart rate recovery after treadmill electrocardiographic exercise stress test and 24-hour heart rate variability in healthy individuals. Arq Bras Cardiol 2008; 90(6): 380-385, http://dx.doi.org/10.1590/s0066$782 \times 2008000600005$.

15. Lyamina N.P., Kotelnikova E.V., Bisyaeva E.A., Karpova E.S. Approaches potentiating cardioprotective effect of ambulatory physical training in patients with ischemic heart disease and multivessel coronary artery involvement after coronary stenting. Kardiologiya 2014; 54(10): 19-25.

16. Akdur H., Yigit Z., Arabaci U., Polat M.G., Gürses H.N., Güzelsoy D. Comparison of cardiovascular responses to isometric (static) and isotonic (dynamic) exercise tests in chronic atrial fibrillation. Jpn Heart J 2002; 43(6): 621-629, http://dx.doi.org/10.1536/jhj.43.621.

17. Sorokin A.P., Vazin A.N., Biryukova O.V. Sposob opredeleniya momenta nastupleniya polnoy adaptirovannosti organizma $k$ fizicheskoy nagruzke [The way to determine the time of complete adaptation of the body to physical exercise].
Avtorskoe svidetel'stvo SSSR 665888 [USSR author's certificate 665888]. 1979.

18. Kamkin A., Kiseleva I., Lozinsky I., Scholz H. Electrical interaction of mechanosensitive fibroblasts and myocytes in the heart. Basic Res Cardiol 2005; 100(4): 337-345.

19. Skards Ya.V., Paeglitis A.O., Matisone D.R. Posledovatel'naya dilatatsiya sosudov soprotivleniya i magistral'nykh arteriy predplech'ya vo vremya rabochey i reaktivnoy giperemii. $\mathrm{V}$ kn.: Krovoobrashchenie $v$ skeletnykh myshtsakh [Sequential dilatation of resistance vessels and major arteries of the forearm during functional and reactive hyperemia. In: Circulation in skeletal muscles]. Riga; 1991; p. 93-105.

20. Delp M.D., O'Leary D.S. Integrative control of the skeletal muscle microcirculation in the maintenance of arterial pressure during exercise. J Appl Physiol (1985) 2004; 97(3): 1112-1118.

21. Yahontov S.V., Kulemzin A.V., Chufistova O.N. Mechanisms and factors link interaction cardiovascular system transient (analytical review, part 1). Vestnik TGPU 2010; 3(93): 149-155.

22. Kapelko V.I. Diastolic dysfunction. Kardiologiya 2011; 51(1): 79-90.

23. Mukumov M.R., Liakhovich Yu.S., Kurchik A.L., Belaya M.L., Pratusevich V.R. The length-dependence of the force-frequency relations in the rat myocardium. Fiziologicheskiy zhurnal SSSR im. I.M. Sechenova 1991; 77(10): 64-68.

24. Korobeynikov G.V., Priymakov A.A. Heart rate variability as physiological mechanism to adapt for strenuous muscular activity conditions. Vestnik Baltiyskoy pedagogicheskoy akademii 2004; 56: 20-26.

25. lellamo F. Neural control of the cardiovascular system during exercise. Ital Heart J 2001; 2(3): 200-212.

26. Mitchell J.H. Neural circulatory control during exercise: early insights. Exp Physiol 2013; 98(4): 867-878, http://dx.doi. org/10.1113/expphysiol.2012.071001. 